\title{
Preliminary data on the performance of Aedes aegypti and Aedes albopictus immatures developing in water-filled tires in Rio de Janeiro
}

\author{
Nildimar Alves Honório/ ${ }^{+}$, Pedro H Cabello*, Cláudia T Codeço**, \\ Ricardo Lourenço-de-O liveira
}

\author{
Laboratório de Transmissores de Hematozoários, Departamento de Entomologia *Laboratório de Genética Humana, \\ Departamento de Genética, Instituto Oswaldo Cruz-Fiocruz, Av. Brasil 4365, 21040-900 Rio de Janeiro, RJ, Brasil **Programa \\ de Computação Científica, Fundação Oswaldo Cruz, Rio de Janeiro, RJ, Brasil
}

A monthly survey of Aedes aegypti and Aedes albopictus immatures in discarded tires at a site in metropolitan Rio de Janeiro showed that Ae. albopictus was much more abundant in the rainy season, but Ae. aegypti abundance showed a less clear seasonal pattern. Pupal masses for Ae. albopictus showed a seasonal trend. In contrast, Ae. aegypti pupae did not show any clear trend in weight. Large Ae. albopictus pupae were found in the warmer months, when water volume was higher, $\mathrm{pH}$ lower, and larval abundance lower. Further studies should be carried out to assess how seasonal variations in body size may impact vector competence of these species in Brazil.

Key words: Aedes aegypti - Aedes albopictus - pupal weight

Aedes albopictus (Skuse) and Aedes aegypti (Linnaeus) are sympatric species that occupy similar ecological niches (Klowden 1993). Immatures of these two vectors feed on microorganisms, fine particulate matter, leaves, and other organic detritus found in water-filled containers. Ae. albopictus can rapidly colonize artificial containers, such as discarded tires and plant vases found in cemeteries, where it potentially interacts with immatures of Ae. aegypti and other mosquitoes (Hawley 1988). Discarded tires are frequently infested with both Ae. aegypti and Ae. albopictus (Suwonkerd et al. 1996) and are considered one of the most productive containers for these mosquitoes.

Several studies have shown that Aedes spp. wing length, and thus body size (Christopher 1960) has a major effect upon the ability of females to store and to synthesize reserves necessary for reproduction (Briegel 1990). This correlation may be one reason for positive relationships between body size and fecundity (Armbruster \& Hutchinson 2002), host-attack rates (Xue et al. 1995), fitness, and vectorial capacity (Nasci 1986).

Size at adulthood increases with pupal weight (Nasci 1991). Pupal weight depends on the amount and quality of resources consumed by the larvae. Per capita resource availability is determined in part by density of larvae in a container. Thus intra-specific and inter-specific competition may have important impacts on both pupal weight and adult body size (Braks et al. 2004). Experimental stud-

Financial support: Fiocruz, CNPq, U.S. National Institute of Health R01 AI-44793, LP Lounibos

Corresponding author: honorio@ioc.fiocruz.br

Received 10 January 2006

Accepted 2 March 2006 ies confirm these predictions (Willis \& Nasci 1994). High larval densities increase resource competition, reduce accumulation of nutritional reserves during larval stages, and reduce pupal weight and adult size (Moore \& Fischer 1969, Juliano 1998).

In this study, we present data from monthly surveys of Ae. aegypti and Ae. albopictus immatures in discarded tires in a dengue-endemic area in the metropolitan area of Rio de Janeiro. Our goal was to evaluate seasonal variation of pupal weight and adult production under natural conditions.

The survey was conducted in Ambaí, a suburban residential area in Nova Iguaçu, metropolitan Rio de Janeiro, Brazil ( $22^{\circ} 45^{\prime} \mathrm{S}$ and $43^{\circ} 27^{\prime} \mathrm{W}$ ), where endemic dengue transmission occurs, mostly during the rainy season from December until April (Schatzmayr 2000) and local Ae. aegypti are highly susceptible to dengue virus and insecticide resistant (Lourenço-de-Oliveira et al. 2004).

Four discarded tires were rinsed with water, dried, sterilized with flame to eliminate mosquito eggs, and then arranged as a pyramid in a house backyard in the first week of October 1997. On the same day, each tire received 21 of water and 30 fallen avocado leaves. Tires were exposed to local rainfall and evaporation. Pupae were sampled during the first week of each month, from November 1997 to October 1998. All water present in each of the four tires was collected, strained through a thin fabric and its volume quantified. Pupae were collected from each tire and the water and avocado leaves returned. In the laboratory, pupae were preserved in $70 \%$ ethanol, identified to species, dried $\left(60^{\circ} \mathrm{C}, 24 \mathrm{~h}\right)$, and individually weighed. $\mathrm{pH}$ was measured using $\mathrm{pH}$ strips (range 0-14, Universalindikator Merck (®). For more details, see Honório and Lourençode-Oliveira (2001). Average air temperature and relative humidity were measured between 10 and 11 a.m. Rainfall data were obtained from the Agro-Meteorological Station of Itaguaí-RJ, at a distance of ca. $20 \mathrm{~km}$ from the study site. Pearson's correlation was used to estimate linear as- 
sociation between water volume, $\mathrm{pH}$, larval abundance, and pupal weight (SPSS for Windows, version 10.0).

We found that the amount of water in the tires closely matched the pattern of rainfall (Figs 1a, b) (Pearson's $r=$ $0.775, \mathrm{p}<0.001)$. In the humid summer months, tires retained 2 to 3.51 of water. In the winter, volumes dropped to values as low as $9 \mathrm{ml}$. In all tires, water was acidic most of the year ( $\mathrm{pH} 5$ to 6.5). In September 1997, $\mathrm{pH}$ increased to near-neutral levels (Fig. 1b). This month coincided with the first rain after the dry winter.

Tires were colonized by four species of Culicidae Ae. albopictus, Ae. aegypti, Limatus durhamii Theobald, and Culex quinquefasciatus Say. Ae. albopictus was the dominant species in all tires, showing significant seasonal trend, with peak in the warmer months. During the late spring-summer season, counts ranged between 600 to 1500 larvae per tire and this species comprised ca. $80 \%$ of the larvae in the community. In the cooler, drier months, counts decreased to 300-600 per tire and its representation dropped to ca. $60 \%$ (Fig. 2a).
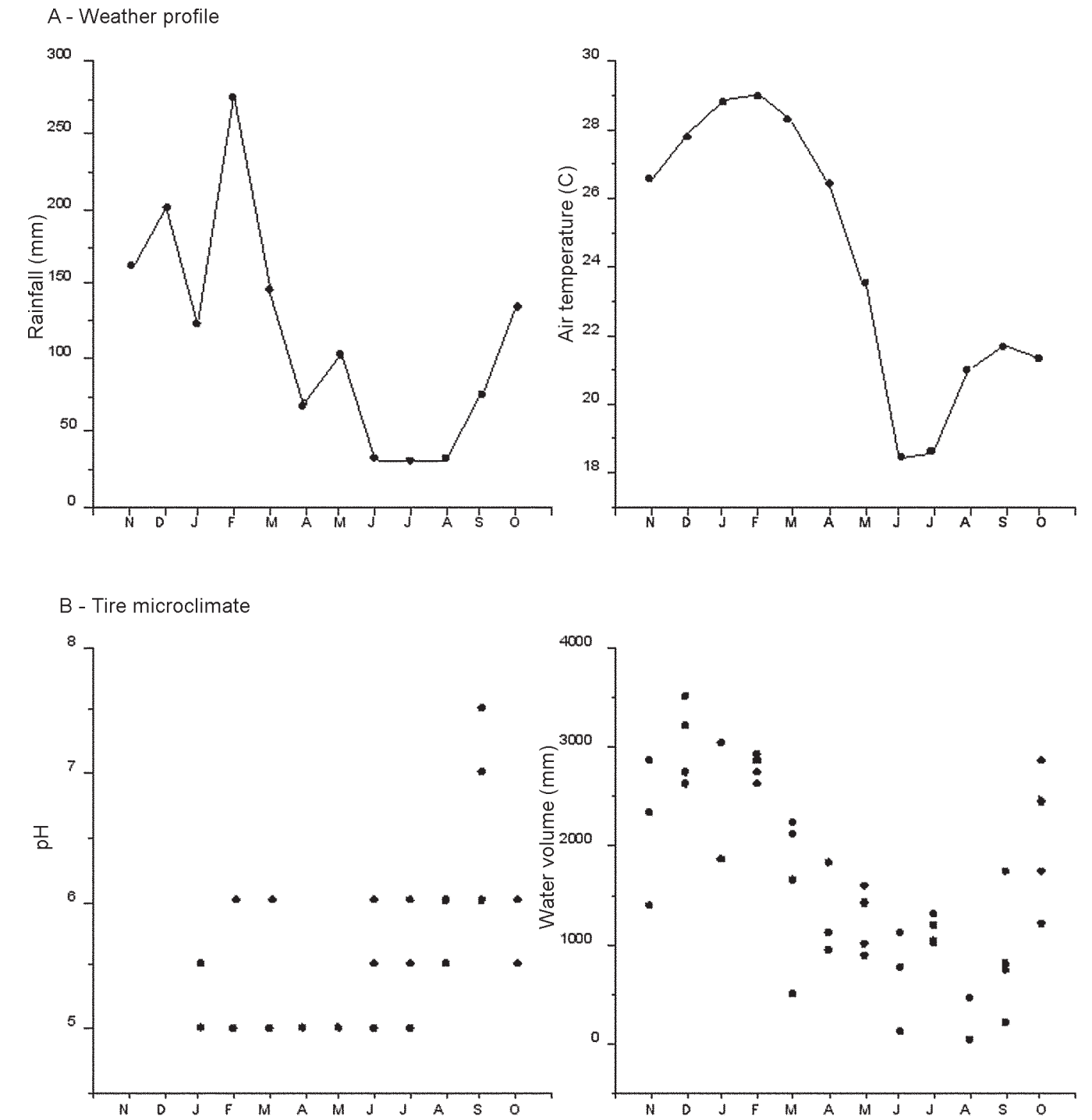

Fig. 1A: average air temperature and rainfall in Ambaí from November 1997 to October 1998; B: pH and water volume in the four tires.
Ae. aegypti, the second most abundant species, showed similar seasonal patterns to those previously reported by Honório and Lourenço-de-Oliveira (2001) and Vezzani et al. (2004). In the summer-early spring months, In the cooler months, counts remained approximately constant at 100 larvae per tire. The only exception was observed in July (Fig. 2a) when abundance of Aedes species was relatively low, and we observed an increasing abundance of L. durhamii (data not shown). Density of larvae (per ml) was stable most of the year. Only during the driest months, when larval count and water volume were the lowest, did larval density increase (Fig. 3B).

Pupae of Ae. albopictus were found throughout the year, and there was a clear seasonal trend of lower densities between March and May. Pupal masses also showed a seasonal trend (Fig. 3A), with smaller pupae in the fall and winter and larger pupae in the warmer months. No significant linear correlation was found between median pupal mass and water volume (Pearson's $\mathrm{r}=-0.02, \mathrm{p}=$ counts oscillated between ca. 100 and 400 larvae per tire. 


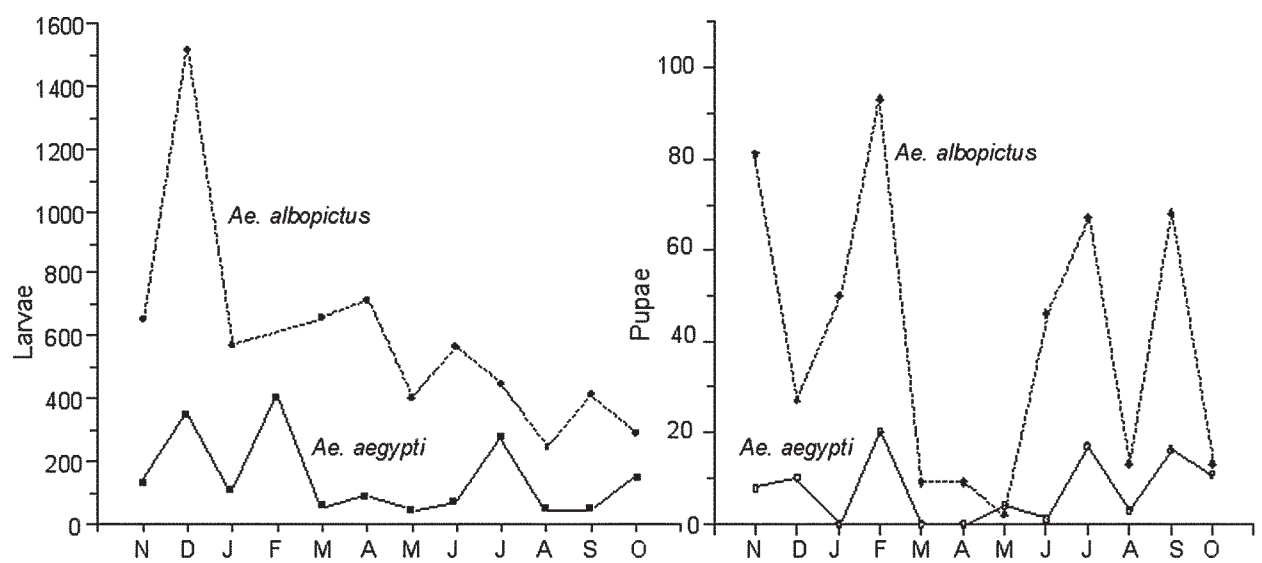

Fig. 2: total number of Aedes aegypti and Ae. albopictus larvae and pupae found in the four tires located at Ambaí, from November 1997 to October 1998.

A
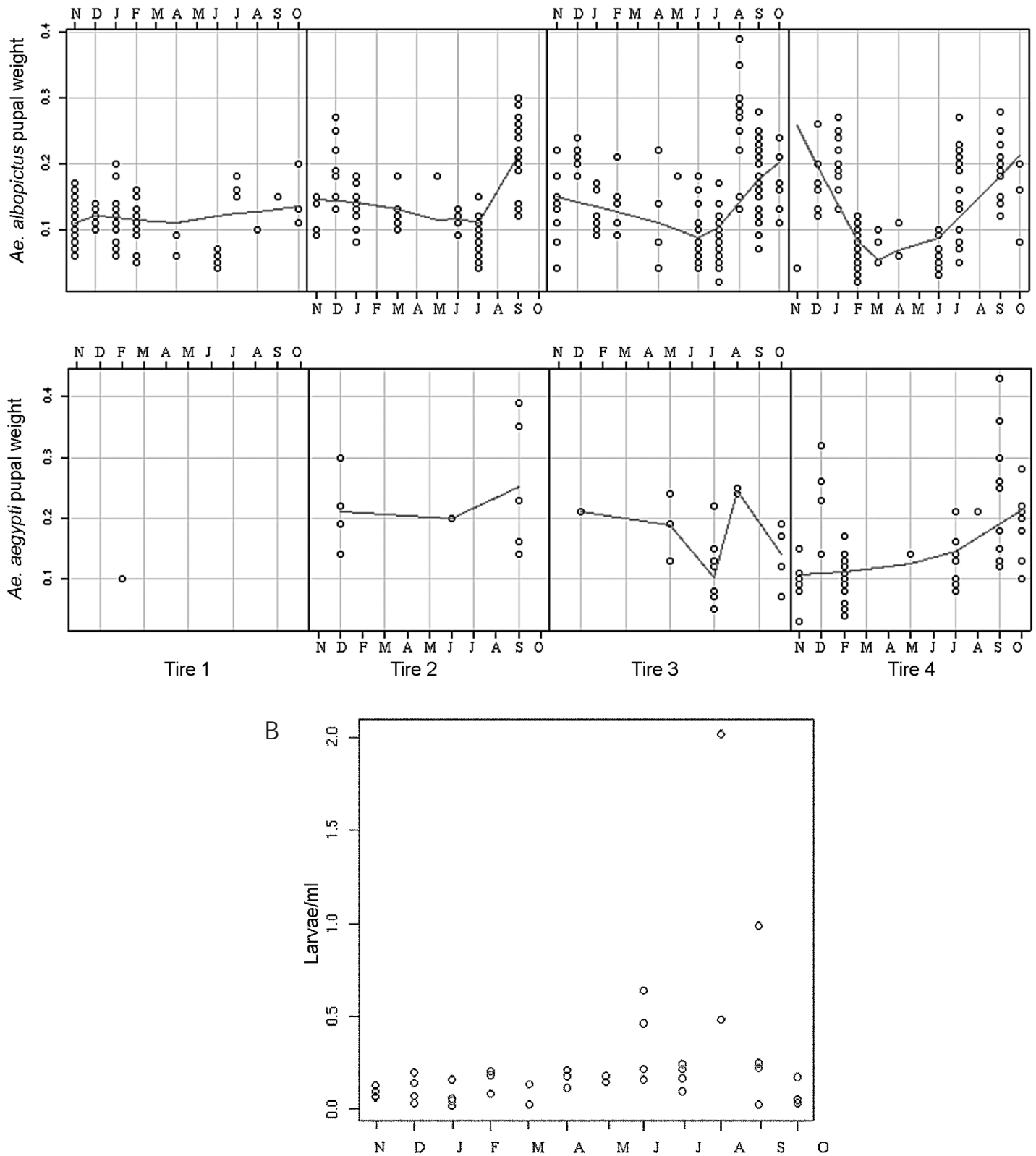

Fig. 3A: median pupal weight of Aedes albopictus and Ae. aegypti pupae found at Ambaí, from November 1997 to October 1998; B: density of larvae in the four tires (larvae/ml), in the same period. 
0.89), temperature (Pearson's $r=0.03, p=0.84$ ), or larval abundance (Pearson's $r=-0.2, p=0.20$ ), maybe due to the high variability and relatively small sample size. $\mathrm{Pu}-$ pae of Ae. aegypti were less abundant and low counts precluded identification of any temporal pattern either in abundance or weight (Figs 2b, 3A).

Ae. albopictus is considered a potential vector of dengue in Brazil (Castro et al. 2004). If this is confirmed, the observed trend towards larger females during the dengue season (summer) may contribute to a higher level of transmission since larger mosquitoes are more fecund (Naksathit \& Scott 1998) and are apparently better vectors in terms of their physiologic capability to acquire dengue infection orally (Sumanochitrapon et al. 1998). Further studies should be carried out to assess how seasonal variations in body size may impact vector competence of these species in Brazil.

\section{ACKNOWLEDGEMENT}

To technicians of Fundação Nacional de Saúde for the logistical support in the field and Drs Steven Juliano, Phil Lounibos, and Marieta Braks for comments on previous versions of the manuscript.

\section{REFERENCES}

Armbruster P, Hutchinson RA 2002. Pupal mass and wing length as indicators of fecundity in Aedes albopictus and Aedes geniculatus. J Med Entomol 39: 699-704.

Braks MAH, Honório NA, Lounibos LP, Lourenço-de-Oliveira $\mathrm{R}$, Juliano AS 2004. Interspecific competition between two invasive species of container mosquitoes, Aedes aegypti and Aedes albopictus (Diptera: Culicidae) in Brazil. Ann Entomol Soc Am 97: 130-139.

Briegel H 1990. Metabolic relationship between female body size, reserves, and fecundity of Aedes aegypti. J Insect Physiol 36: 165-172.

Castro MG, Nogueira RMR, Schatzmayr HG, Miagostovich MP, Lourenço-de-Oliveira R 2004. Dengue virus detection by using reverse transcription polymerase chain reaction in saliva and progeny of experimentally infected Aedes albopictus from Brazil. Mem Inst Oswaldo Cruz 99: 809814.

Christopher SR 1960. Aedes aegypti (L.). The Yellow Fever Mosquito, Cambridge University Press, London, 739 pp.

Hawley WA 1988. The biology of Aedes albopictus. J Am Mosq Control Assoc 4 (Suppl. 1): 1-40.

Honório NA, Lourenço-de-Oliveira R 2001. Freqüência de larvas e pupas de Aedes aegypti e Aedes albopictus em armadilhas, Brasil. Rev Saúde Púb 34: 385-391.

Juliano SA 1998. Species introduction and replacement among mosquitoes: interespecific resource competition or apparent competition? Ecology 79: 255-268.

Klowden MJ 1993. Mating and nutritional state affect the reproduction of Aedes albopictus mosquitoes. J Am Mosq Control Assoc 2: 169-173.

Lourenço-de-Oliveira R, Vazeille M, Filippis AMB, Failloux AB 2004. Aedes aegypti in Brazil: genetically differentiated populations with high susceptibility to dengue and yellow fever viruses. Trans $R$ Soc Trop Med Hyg 98: 43-54.

Moore CG, Fischer BR 1969. Competition in mosquitoes: density and species ratio effects on growth mortality, fecundity and production of a growth retardant. Ann Entomol Soc Am 62: 1325-1331.

Naksathit AT, Scott TW 1998. Effect of female size on fecundity and survivorship of Aedes aegypti fed only human blood versus human blood plus sugar. J Am Mosquito Control Assoc 14: 148-152.

Nasci RS 1986. The size of emerging and host-seeking Aedes aegypti and the relation of size to blood-feeding success in the field. J Am Mosq Control Assoc 2: 61-62.

Nasci RS 1991. Influence of larval and adult nutrition on biting persistence in Aedes aegypti (Diptera: Culicidae). J Med Entomol 28: 522-526.

Schatzmayr HG 2000. Dengue situation in Brazil by year 2000. Mem Inst Oswaldo Cruz 95 (Suppl. 1): 179-181.

Sumanochitrapon W, Strickman D, Sithiprasasna R, Kittayapong P, Innis BL 1998. Effect of size and geographic origin of Aedes aegypti on oral infection with dengue-2 virus. Am J Trop Med Hyg 58: 283-286.

Suwonkerd W, Tsuda Y, Takaji M, Wada Y 1996. Seasonal occurence of Aedes aegypti and Aedes albopictus in used tires in 1992-1994, Chiangmai, Thailand. Trop Med 38: 101105.

Vezzani D, Velázquez SM, Schweigmann N 2004. Seasonal pattern of abundance of Aedes aegypti (Diptera: Culicidae) in Buenos Aires City, Argentina. Mem Inst Oswaldo Cruz 99: 351-356.

Willis FS, Nasci RS 1994. Aedes albopictus (Diptera: Culicidae) population density and structure in Southwest Louisiana. $J$ Med Entomol 31: 594-599.

Xue RD, Barnard DR, Schreck CE 1995. Influence of body size and age of Aedes albopictus on human host attack rates and the repellency of deet. J Am Mosq Control Assoc 11: 50-53. 